\title{
Prevalence, risk factors and correlation with cardiac involvement of carpal tunnel syndrome in amyloidosis
}

\author{
Agnese Milandri ${ }^{1 *}$, Simone Longhi ${ }^{1}$, Christian Gagliardi ${ }^{1}$, Mario Cinelli ${ }^{1}$, Serena Foffi', Ilaria Bartolomei ${ }^{2}$, \\ Fabrizio Salvi ${ }^{2}$, Claudio Rapezzi ${ }^{1}$ \\ From First European Congress on Hereditary ATTR amyloidosis \\ Paris, France. 2-3 November 2015
}

\section{Background}

Carpal tunnel syndrome (CTS) is one of the most common clinical manifestations of TTR-related amyloidosis, both hereditary (ATTR), and wild type (senile systemic amyloidosis, SSA) and often precedes cardiac symptoms. The exact prevalence of CTS in light-chain amyloidosis (AL), ATTR and SSA is not known. We therefore aimed to establish prevalence, risk factors and possible association with cardiac involvement in patients with TTRrelated and AL amyloidosis.

\section{Methods}

We retrospectively analyzed clinical and instrumental (ECG and echocardographic) findings of 260 patients with TTR-related, and 175 with AL amyloidosis evaluated at our Centre between 1990 and September 2013.

\section{Results}

Prevalence was 35\% in TTR-related amyloidosis (35\% in ATTR and $32 \%$ in SSA) and $8 \%$ in patients with AL $(\mathrm{p}<0.001)$. Among TTR patients, CTS was more frequently associated with cardiac involvement $(76 \%$ vs. $42 \%$; $<0.0001$ ) as reflected by the presence of pathological ECG and echocardiogram. Moreover, CTS manifested 9 years before the onset of cardiac symptoms. Among patients with cardiomyopathy with/without CTS there were no significant clinical/instrumental differences. At univariate analysis male gender and genotype were not associated with CTS.

'Diagnostic and Specialty Medicine - DIMES, Alma Mater Studiorum,

University of Bologna, Cardiology, 40138, Bologna, Italy

Full list of author information is available at the end of the article

\section{Conclusion}

CTS is specifically associated with TTR-related (but not $\mathrm{AL}$ ) amyloidosis independently from patient gender. In TTR-related amyloidosis, CTS is more frequently associated with cardiac involvement, even though patients with cardiomyopathy with/without CTS have a comparable clinical/instrumental profile. CTS precedes cardiac symptoms onset by 9 years and this awareness is important for an early diagnosis of amyloidotic cardiomyopathy.

\section{Authors' details}

'Diagnostic and Specialty Medicine - DIMES, Alma Mater Studiorum, University of Bologna, Cardiology, 40138, Bologna, Italy. ${ }^{2}$ Bellaria Hospital, Neurology, 40100, Bologna, Italy.

Published: 2 November 2015

doi:10.1186/1750-1172-10-S1-P32

Cite this article as: Milandri et al:: Prevalence, risk factors and

correlation with cardiac involvement of carpal tunnel syndrome in amyloidosis. Orphanet Journal of Rare Diseases 2015 10(Suppl 1):P32.

Submit your next manuscript to BioMed Central and take full advantage of:

- Convenient online submission

- Thorough peer review

- No space constraints or color figure charges

- Immediate publication on acceptance

- Inclusion in PubMed, CAS, Scopus and Google Scholar

- Research which is freely available for redistribution

Submit your manuscript at www.biomedcentral.com/submit
() Biomed Central 